\title{
WNT4 and RSPO1 Are Not Involved in a Case of Male-to-Female Sex Reversal with Partial Duplication of 1p
}

\author{
P. Wieacker M. Volleth \\ Institute of Human Genetics, Otto von Guericke University, Magdeburg, Germany
}

\section{Key Words}

Duplication $1 \mathrm{p} \cdot \mathrm{RSPO} 1 \cdot$ Sex reversal $\cdot$ WNT4

\begin{abstract}
Some studies suggest that WNT4 signaling acts to repress the male pathway and a single case of duplication of WNT4 located in 1p35 has been associated with ambiguous genitalia. Recently, RSPO1 located in 1p34.3 was shown to be essential in sex determination. We show that neither WNT4 nor RSPO1 are duplicated in another case of male-to-female sex reversal with partial duplication of $1 \mathrm{p}$. Therefore, it can be assumed that in male-to-female sex reversal associated with duplication of $1 p$, other genetic factors may be involved.
\end{abstract}

Copyright $\odot 2007$ S. Karger AG, Basel

XY gonadal dysgenesis can be caused by a disturbed development of the bi-potential gonad or by failure of differentiation of the bi-potential gonad to testis [for a review see Fleming and Vilain, 2004]. Genes known to be involved in human early gonad development are WT1 and SF1. The key gene of testis differentiation is $S R Y$, a transcription factor with hitherto unknown target genes. $S R Y$ expression in supporting cells leads to their differentiation into Sertoli cells, and it is believed that a critical threshold number of Sertoli cells are required for testis differentiation. SOX9 seems to be the next gene downstream of $S R Y$ that is upregulated in Sertoli cell precursors. DAX1 is thought to antagonize SRY action as duplication of DAX1 causes male-to-female sex reversal, and Jordan et al. [2001] presented evidence that WNT4 overexpression leads to upregulation of $D A X 1$. In their study, they describe one patient with ambiguous external genitalia and a male karyotype with partial duplication of $1 p$ including WNT4. Here, we report on another patient with partial duplication of $1 \mathrm{p}$ and complete male-to-female sex reversal, but show that WNT4 is not duplicated in this case. We also show that RSPO1, a gene recently implicated in human sex determination [Parma et al., 2006], is not included in the duplication.

\section{Case Report}

The phenotype of the patient has been described by Wieacker et al. [1996]. At 10 years of age growth development was retarded (height and weight $<3$ rd centile) and psychomotor development was severely impaired. Dysmorphic features include epicanthal folds, ptosis, hypertelorism, depressed nasal bridge, anteverted nares, higharched palate, supernumerary nipples, simian crease on

\section{KARGER}

Fax +41613061234

E-Mail karger@karger.ch

www.karger.com
(C) 2007 S. Karger AG, Basel

1661-5425/07/0012-0111\$23.50/0

Accessible online at:

www.karger.com/sxd
Prof. Dr. med. Peter Wieacker

Institut für Humangenetik, Universitätsklinikum Magdeburg

Leipziger Strasse 44, DE-39120 Magdeburg

Tel. +4939167 15062, Fax +493916715066

E-Mail peter.wieacker@medizin.uni-magdeburg.de 


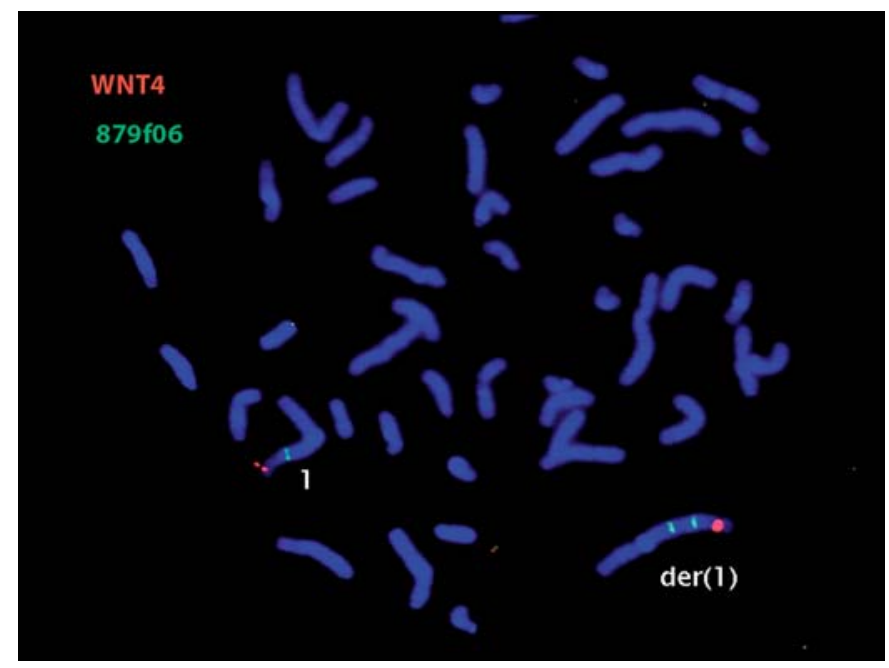

Fig. 1. Two-color-FISH with the YAC clone 879f06 situated within the duplicated region on the short arm of chromosome 1 labeled in green and with the P1 clone containing WNT4 labeled in red. The derivative chromosome shows two green signals but only one red signal, indicating that WNT4 is not duplicated in this patient.

the right hand, and nail dysplasia. Computer tomography revealed hypoplasia of the corpus callosum and mild hydrocephalus. External genitalia are female and sonography revealed the presence of a uterus, but gonads could not be visualized. Endocrine parameters demonstrate a hypergonadotropic hypogonadism. Chromosome analysis revealed a male karyotype with partial duplication of 1p: 46,XY,dup(1)(1p22.3p32.3). Parental karyotypes were normal.

\section{Materials and Methods}

The YAC clone 879f06 and the RSPO1-containing BAC clone RP11-566C13 were obtained from the Molecular Cytogenetic and Positional Cloning Center of the Max-Planck-Institute for Molecular Genetics, Berlin. The P1 clone containing WNT4 was a gift of E. Vilain (Los Angeles, USA).

DNA probes were labeled directly by nick translation with SpectrumOrange-dUTP or SpectrumGreen-dUTP (Abbott, Illinois, USA). Labeled YAC clones were dissolved in hybridization mixture (50\% formamide, $2 \times$ SSC, $10 \%$ dextran sulfate). After hybridization, metaphases were counterstained with DAPI and viewed with selective filters. Images were captured with the Cytovision digital imaging system (Applied Imaging, Sunderland, $\mathrm{UK})$.

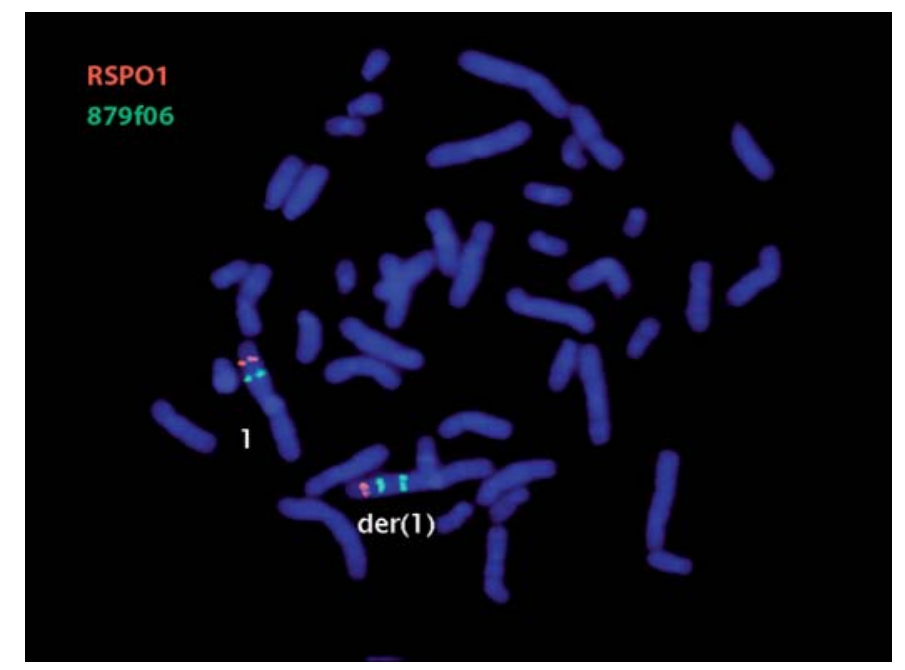

Fig. 2. Two-color-FISH with the YAC clone 879 f06 situated within the duplicated region on the short arm of chromosome 1 labeled in green and with the BAC clone RP11-566C13 containing RSPO1 labeled in red. As in fig. 1, the derivative chromosome shows two green signals but only one red signal, indicating that RSPO1 is not duplicated.

\section{Results}

The results of FISH analysis on metaphase spreads from the patient with the P1 clone containing WNT4 and YAC clone 879f06 which contains the markers D1S462 and D1S192 located in 1p31.1 are given in fig. 1 . Whereas two signals can be detected with YAC clone $879 \mathrm{f} 06$ on the derivative chromosome 1, there is only one WNT4 signal located distal from the duplication. Similar results were obtained by FISH analysis with BAC clone RP11-566C13 containing RSPO1. Only one RSPO1 signal could be detected on the derivative chromosome 1 , whereas two signals for YAC 879f06 were visualized (fig. 2). These results clearly demonstrate that neither WNT4 nor RSPO1 are involved in the partial $1 \mathrm{p}$ duplication in the patient.

\section{Discussion}

Many studies suggest that the supporting cell precursor lineage is bi-potential with the possibility to develop into follicle cells or Sertoli cells. Kim et al. [2006] showed that Fgf9 (fibroblast growth factor 9) and Wnt4 are expressed in both XX and XY gonads at $11.25 \mathrm{dpc}$ in mice and proposed that $F g f 9$ and Wnt4 act as antagonistic signals to regulate sex determination. Mice homozygous for 
a loss of function mutation in Fgf9 display male-to-female sex reversal including failure of Sertoli cell differentiation. In contrast, XX gonads with a loss of function mutation in Wnt4 show some features of testis differentiation [Jeays-Ward et al., 2003]. According to the concept of Kim et al. [2006], Sox9 upregulates Fgf9, and Fgf9 maintains Sox 9 expression in a feed-forward loop and represses Wnt4 expression leading to male gonad differentiation. In the absence of a feed-forward loop between Sox 9 and $F g f 9$, as it is the case in XX gonads, Wnt 4 blocks Fgf9 and the maintenance of Sox 9 expression leading to female gonad differentiation.

On the basis of such an antagonistic system between Fgf9 and Wnt4 it can be expected that overexpression of Wnt4 may lead to male-to-female sex reversal. In fact, Jordan et al. [2001] could show that Wnt4 upregulates Daxl, a gene known to antagonize Sry, and WNT4 was duplicated in a patient with ambiguous genitalia and partial duplication of the short arm of chromosome 1 (1p31p35). However, FISH analysis of WNT4 in our patient clearly demonstrates that WNT4 is not duplicated. Therefore, it is unlikely that WNT4 is involved in the pathogenesis of sex reversal in this patient. A position effect with upregulation of WNT4 cannot be ruled out, but the distance of more than $28 \mathrm{Mb}$ between the distal duplication breakpoint at 1p32.3 and WNT4 at 1p35 makes this option highly unlikely.
Recently, Parma et al. [2006] could show that homozygous loss of function mutation of RSPO1 encoding Rspondin1 causes female-to-male sex reversal associated with palmoplantar hyperkeratosis and predisposition to squamous cell carcinoma of the skin. R-spondin1 is a member of a family of orphan ligands that activate Wnt and $\beta$-catenin signaling pathways. Obviously, the absence of any functional RSPO1 copy leads to testis differentiation of XX gonads, possibly because of inactivation of the ovarian WNT4 pathway. Because a possible interaction between WNT4 and RSPO1 has been suggested [Parma et al., 2006], we performed FISH analysis with a BAC clone containing RSPO1 that is located in 1p34.3. As expected from the extent of the duplication from $1 \mathrm{p} 22.3$ to $1 \mathrm{p} 32.3, \mathrm{RSPO} 1$ is not involved in the duplication. Thus, sex reversal in our patient is not caused by alterations of WNT4 or RSPO1 gene dosage, and we suggest that other loci may be involved in the pathogenesis of this disorder of sex differentiation.

\section{Acknowledgement}

This work was supported by a grant of the Bundesministerium für Bildung und Forschung (BMBF).

\section{References}

Fleming A, Vilain E: The endless quest for sexdetermining genes. Clin Genet 67:15-25 (2004).

Jeays-Ward K, Hoyle C, Brennan J, Dandonneau M, Aldus G, et al: Endothelial and steroidogenic cell migration are regulated by WNT4 in the developing mammalian gonad. Development 130:3663-3670 (2003).
Jordan BK, Mohammed M, Ching ST, Delot E, Chen XN, et al: Up-regulation of WNT4 signaling and dosage-sensitive sex reversal in humans. Am J Hum Genet 68:1102-1109 (2001).

Kim Y, Kobayashi A, Sekido R, DiNapoli L, Brennan J, et al: Fgf9 and Wnt4 act as antagonistic signals to regulate mammalian sex determination. PLoS Biol 4:1000-1009 (2006).
Parma P, Radi O, Vidal V, Chaboissier MC, Dellambra $\mathrm{E}$, et al: R-spondin1 is essential in sex determination, skin differentiation and malignancy. Nat Genet 38:1304-1309 (2006).

Wieacker P, Missbach D, Jakubiczka S, Borgmann S, Albers N: Sex reversal in a child with the karyotype 46,XY,dup(1)(p22.3p32.3). Clin Genet 49:271-273 (1996). 